on to arrest epidemics; if they may use police power to abate nuisances destructive of health or life, this power and this function ought to be called in play to exterminate this deathdealing book.

The antiquated text-book of medicine is a positive and widespread danger to society. It perpetuates and makes active the baleful influence of our medical forbears. This influence is greater the greater the authority and the more permanent the position of the author. If a man has done his work before he is 50 and ought then to step aside and give place to the young, the medical text-book has outlived its usefulness in one-tenth that time. The libraries of sixty thousand physicians are encumbered, their practices vitiated and their patients put to unnecessary suffering and danger by the sixty thousand antiquated Oslers. How boldly the vanquished physician standing at the bedside of his unfortunate patient quotes, to his complacency and the palliation of his defeat, the dictum of an Osler of the edition of 1894, and with what humility, not to say astonishment, would he read the reversal of that opinion in the last edition! The antiquated textbooks of medicine of ten years ago, especially those that treat of the care of infants and the treatment of genito-urinary diseases and general medicine, are now supporting the pernicious practices of an army of physicians, in whose hands they cause uncalled-for and immeasurable suffering and no small mortality. These old books, however, maintain an unquestioned dignity and respectability, while the automobile and cigarette call forth columns of malignant abuse, interminable persecution and drastic legislation. Single lines have been followed by a weeping and limping procession, which the repeated recantation of the author in subsequent editions and the earnest and dramatic teaching in class room, lecture hall and journal has been unable to arrest. The curse of modern medical book selling is the antiquated text-book. The book agent foists his wares on the indulgent physician who scarcely turns in his last payment on a good book before it is superceded by another edition made necessary by the rapid advance in medical diagnosis and treatment. Since we have referred to Osler, let us take as illustrations the diagnosis and treatment of any of the diseases of the abdominal viscera in the last edition and the edition of ten years ago. Could there be a greater contrast between the teachings of any medical sect and that of rational medicine than between Osler's own account of the non-malignant diseases of the stomach, the diseases of the biliary apparatus, dysentery and appendicitis $^{1}$ in these two editions? Nevertheless we hear the Osler of ten years ago quoted ex cathedra in every medical society and often at the bedside with no appreciation of its melancholy import. Should an attorney quote the decision of a court which had for ten years been reversed, he would be sharply corrected by the opposing counsel. The patient's advocate, the physician, meets, unfortunately, a silent plaintiff in a court of unquestioned justice. When he meets defeat he departs, often unconscious of his remissions, and even the autopsy fails by its rarity and novelty to jolt the complacent and luck-trusting practitioner into the serious consideration of the rapid advance of his art.

104 East Fortieth Street.

Bayard Holmes, M.D.

\section{Acetozone Solutions.}

New Haven, Cons., Dec. 3, 1905.

To the Editor:-I am anxious to learn if any one else has had any experience in the use of acetozone solutions for injection into the spinal canal after lumbar puncture in cerebrospinal meningitis. I have used it recently with apparently good results in two severe and protracted cases. In both these cases puncture had already been required to relieve urgent pressure symptoms, but, while successful in this respect, the procedure had been without effect on the temperature. After the acetozone injections this remained nearly normal, A weak solution ( 5 grains to quart) was used, the patients being aged 7 and 4 respectively. In the first case 30 c.c. of fluid were withdrawn and 15 c.c. of the acetozone solution injected; in the second case 35 c.c. were withdrawn and 15 c.c. injected. In

1. "The medical treatment of appendicitis can be expressed in three words-rest, opium and enemata." the acute fulminating cases, in which death takes place before the formation of much fluid, such injection would be difficult and probably ineffectual. Probably stronger solutions can be used. Louis S. De Forest.

Is the Bituminous Coal Miner Immune from Tubercular Infection While Actively Engaged in His Occupation?

DuQuoin, ILL., Nov. 21, 1905.

To the Editor:-After an experience of 25 years in one of the largest coal mining towns in southern Illinois, and during this time having under my observation from 700 to 1,200 coal miners; and after careful enquiry among the oldest miners in this locality as to the number of coal miners that have been infected with this dreadful disease, I have been forced to the conclusion that bituminous coal miners, while actively engaged in their occupation, are practically immune from tubercular infection.

About seven years ago I commenced the treatment of whooping cough by sending the patient down in the mines immediately after the miners had fired a shot; having the patient inhale the gas and powder smoke for one and a half to two hours at a time. I found that one or two sittings was sufficient to effect a cure in from four to six days, and without other medicine.

This was followed up until I have on my records from 75 to 100 cases, ranging in age from 3 months to 27 years. This treatment has passed so far as my experience goes, from the experimental stage to the stage of confirmation. It is so successful and is now so well known in this locality, the miners take their children so affected into the mines, with. out consulting a physician, and always with the happiest results.

In June, 1905, I obtained from the coal operators "Blue Book," and from a United States medical directory the addresses of 600 physicians practicing in the coal mining towns of Illinois, Indiana, Ohio, Pennsylvania and West Virginia. I carefully selected the names of those who had practiced not less than 10 years, and sent to them a circular letter containing four questions, and enclosing with each a stamped, addressed envelope for reply, in order that I might gather from their experience some statistics on the liability of coal miners to tubercular infection, while actively engaged in their occupation. The following is the text of the body of the letter and the four questions:

Dear Doctor:-In order to obtain statistical information from those of my professional brothers who can speak from experience and observation concerning the frequency and liability of infectious tuberculosis among coal miners as a class, I respectfully submit the following questions:

1. How much professional experience have you had among coal miners?

2. About what per cent. of all coal miners who have come under your professional observation have had infectious tuberculosis?

3. About what per cent. of those who, of your own knowledge, had been exposed to tuberculosis have been infected?

4. Taking into consideration their usual habits of life, together with their daily exposure, do you consider coal miners, as a class, immune from tubercular infection while actively engaged in their occupation?

As a result of these inquiries $I$ have thus far received in reply over two hundred letters. Of this number about 75 per cent. give as their experience and observation, that during active service in his occupation the bituminous coal miner is immune, wholly or in part.

M. C. CARR, M.D.

The Psychopathic Manifestations of the Non-Insane Psychoneuroses.

New Yonk, Dec. 8, 1905.

To the Editor:- In the valuable article under the above title in The Jovrnal, December 2, Dr. John Punton makes some timely remarks on inexact nomenclature. I wish to add some suggestions: As physicians giving the word in our own lan- 